\title{
Laboratory Investigation on the Effect of Microsilica Additive on the Mechanical Behavior of Deep Soil Mixing Columns in Saline Dry Sand
}

\author{
Morteza Esmaeili ${ }^{1 *}$, Farshad Astaraki ${ }^{2}$, Hamed Yaghouti ${ }^{1}$, Majid Movahedi Rad ${ }^{2}$ \\ ${ }^{1}$ Department of Track and Structures, School of Railway Engineering, Iran University of Science and Technology, 13114-16846 \\ Tehran, Iran \\ 2 Department of Structural and Geotechnical Engineering, Faculty of Architecture, Civil Engineering and Transport Sciences, Széchenyi \\ István University, Egyetem tér 1, 9026 Győr, Hungary \\ *Corresponding author, e-mail: M_esmaeili@iust.ac.ir
}

Received: 02 March 2021, Accepted: 26 May 2021, Published online: 18 June 2021

\begin{abstract}
Since loose and salty subgrades consider as problematic barriers while constructing new transportation infrastructures such as railway tracks and roads are required, the current study aims to find a solution to stabilize these kinds of subgrades using the deep soil mixing (DSM) technique and micro silica additive. In the present study a series of experimental DSM columns were executed in a salty sand-filled chamber utilizing a laboratory scale DSM apparatuses. In the first step, by adding three salt percentages of 5, 10 and 20 into the original sand, four different sandy subgrades with a relative density of $70 \%$ were prepared. Considering three percentages of 10, 15 and 20 for micro silica additive, the water-to-cement ratio of 1, salt percentages of 0, 5, 10 and 20 totally 150 sand-cement columns were constructed in the lab environment. In continuation, unconfined compression strength (UCS) and elasticity modulus of all capped DSM columns have been determined and interpreted using scanning electron microscope (SEM) images at three ages of 7,14 and 28 days. The results indicated that increasing the salinity of subgrade soil from 0 to $20 \%$ resulted in a falling UCS and Young module by 28 and $21 \%$ for 28-days specimens. Furthermore, as a solution, adding micro silica in cement-water grout up to $15 \%$ resulted in enhancing mechanical characteristics of the DSM columns. So that adding 15\% microsilica caused a 21 and $42 \%$ increase in UCS and elasticity modulus of 28-days samples respectively, executed in subgrade with $20 \%$ salt.
\end{abstract}

\section{Keywords}

deep soil mixing columns, loose salty-sand subgrades, microsilica additive, unconfined compression strength, elasticity modulus

\section{Introduction}

Salinity refers to presence of $\mathrm{NaCl}, \mathrm{SO}_{4}{ }^{2-}$ etc. ions in soil. Salts are crystalline compounds that convert to ion when dissolved in water. A large portion of the world including some parts of Iran, Australia, Saudi Arabia, Algeria, Morocco, China, the United State and South Africa has been covered by saline soils, which makes the importance of improving these soils twofold. From geotechnical engineering point of view, constructing new infrastructures on saline subgrades have been faced many difficulties. Stability and strength of structural elements contacted with saline soils can be rigorously affected. For instance, when superstructures are built on foundation with saline soils, their bearing capacity decreases while the foundation periodically is moistened [1]. Presence more than 5\% salt in saline soils has a significant effect on their mechanical properties [2]. In order to reclaim mechanical and chemical properties of salty soils a growing body of studies has been conducted using different techniques including electrochemical improvement and chemical improvement by adding cement, lime, fly ash and micro silica or adopting mechanical stabilization by insertion of geotextile material [3-10]. Effect of sodium chloride on the mechanical properties of cement-stabilized Lianyungang marine clay was investigated by Abduljauwad et al. [3]. In this laboratory research, a series of UCS tests were performed on the specimens, which were made by various sodium chloride and ordinary Portland cement. The result indicated that the presence of sodium chloride in soil had a negative effect and decreased both UCS and elasticity modulus of the cementclay mixture. Jayasekera and Hall [11] examined an in-situ 
soil treatment technique based on electro kinetics principles to improve mechanical properties of saline-sodic soil. The main results indicated that using electro kinetic treatment alone and with lime increased compressive strength of the soil by 100 and 200\% respectively. Moreover, they found out that compressive strength of the soil was affected by soil type, clay content and different complex electrochemical processes. An experimental study performed on mechanical behavior of sulphate saline soil as high-speed railway subgrade. In this study, effect of various salt contents without lime and different lime proportion for a fixed amount of salt on unconfined compressive strength of the sulphate saline soil was examined. The result showed that salt content of $5.5 \%$ and lime portion of $8.5 \%$ resulted in maximum unconfident compressive strength for unimproved an improved soil respectively. The effect of lime addition was so striking that the increase was 10 times more than the unimproved soil [12]. Another experimental study was carried out in scope of salty soil treatment to find out the effect of Metakaolin (MK) on the mechanical characteristic of cement-treated salty soft soil [13]. It was clarified that the strength of soil-cement samples increased by growing the amount of Metakaolin. The optimum amount of MK was found 3,4 and 5\% depended on ion content in each case. Besides, the strength of salt-rich soil-cement decreased while the ion content increased so that the MK couldn't eliminate the negative effect of ions.

On the other hand, ground improvement techniques such as stone columns, jet grouting and DSM are frequently used to improve problematic soils in depth. Among deep improvement methods, the DSM method with different slurry and additive like cement, microsilica, fly ash, lime and etc. has received much attention from geotechnics and geology researchers [14-23]. For instance, the effect of salt in loose soil was studied on soil improvement adopting deep soil mixing method with cement slurry. For this purpose, a series of laboratory and field tests were done to investigate UCS of soil-cement columns considering different content of $\mathrm{SO}_{4}{ }^{2-}, \mathrm{Mg}^{2+}, \mathrm{Cl}^{-}$, water, cement and salt. It was found that increasing cement content led to gain in UCS and adding water had the reverse result. Furthermore, adding different amount of $\mathrm{SO}_{4}{ }^{2-}, \mathrm{Mg}^{2+}, \mathrm{Cl}^{-}$, despite affecting the microstructure of the specimens, resulted in declined soil-cement UCS [24]. Al-Tabba et al. [14] studied the effectiveness of DSM method in layered sands by considering two different types of blade and different sand stratifications, two different grouts and different installation techniques. The UCS tests result indicated that the optimum cement-pulverized fuel ash (PFA) soil-grout mix consisted 3.5 and $10 \%$ for cement and PFA respectively and this amount was 10 and $1 \%$ for cement and bentonite respectively for cement-bentonite soil-grout mixture. In another study, Esmaeili et al. [22] conducted a series of laboratory tests to find out the effect of microsilica additive on bearing capacity of DSM columns. To do this many experimental DSM columns installed in a loose sandy soil with different water to cement ratio (W/C) and microsilica percentages. The results indicated that cement slurry with $\mathrm{W} / \mathrm{C}$ of 1 and $15 \%$ microsilica additive showed the maximum bearing capacity in terms of UCS.

Whilst some research has been carried out on the treatment of saline soils, a limited studies have investigated the application of DSM columns using micro silica additive to improve the mechanical properties of the mentioned soils. The main objective of this experimental study is to find out the effect of salt amount on UCS and elastic modulus of soil-cement columns and investigate the application of microsilica additive on the mentioned parameters for saline soils. In this matter, in an experimental study by utilizing a DSM apparatus in laboratory scale with 6-blades hollow rod, totally 150 sand-cement columns were executed considering four salt percentages of $0,5,10$ and 20, a water-cement ratio of 1 , three micro silica percentages of 10,15 and 20 and three curing ages of 7, 14 and 28 days to monitor the mechanical behavior of soil-cement columns with uniaxial loading device in conjunction with SEM images of columns' samples. The outcomes of the research are presented in the form of UCS and elasticity modulus of the columns.

\section{Plan of experiments}

\subsection{Material properties}

The material used in this study are sand, salt, cement and micro-silica which their properties will be presented in detail in the following. In order to install soil-cement columns in the lab environment, DSM machine developed and equipped in IUST was employed. Different elements of the machine and also the DSM columns execution process will be discussed in the next steps.

\subsubsection{Sand properties}

In this study, poorly graded sand (SP) of Firoozkhoh query in the vicinity of Tehran city with the particle size of 0.4-1 mm which showed improper engineering behavior in many geotechnical applications [25], was used for the preparation of loose sandy soil bed in the lab. Fig. 1(a) addresses the particle size distribution curve of used sand. 
Table 1 likewise presents the mechanical and physical properties of the SP based on laboratory tests which have been carried out by authors [22].

\subsubsection{Salt, cement and micro silica properties}

In order to prepare saline soil subgrade, salt was taken from Qom lake with given chemical compositions in Table 2. It should be pointed out the presented properties of the salt have been extracted from X-ray Fluorescence (XRF) analysis. Type II Ordinary Portland cement (OPC) which is widely used for engineering purposes was selected as the main part of injecting slurry. Fig. 1(b) shows grain size distributed curve obtained accordance with ASTM D422-63 [30].

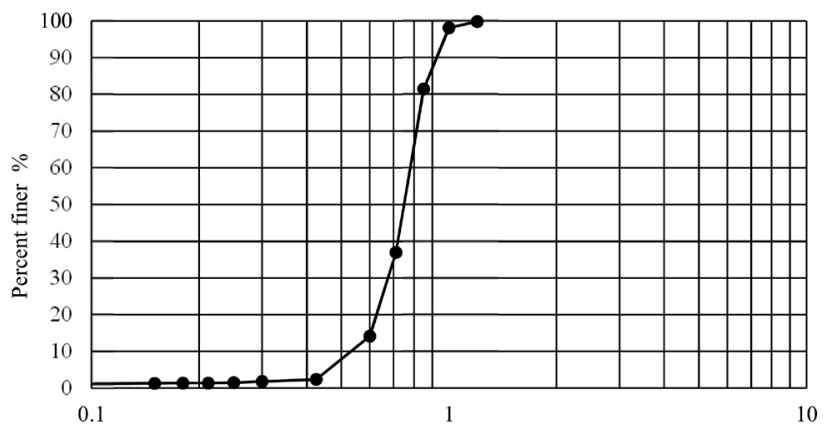

Grain Size (Log-mm)

(a)

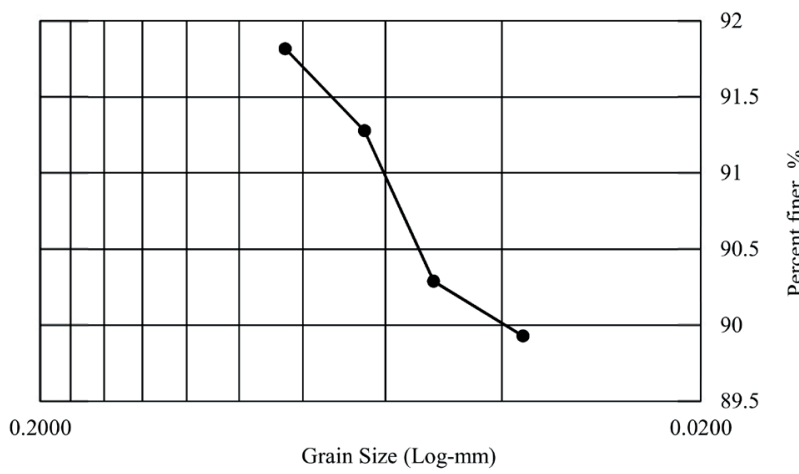

(b)

Fig. 1 Particle size distribution curve of (a) the SP sand and (b) Portland cement type 2

Table 1 Material properties of poorly graded sand (SP)

\begin{tabular}{|c|c|c|c|c|}
\hline Parameter & Symbol & Unit & Value & Relavant Standard \\
\hline Cohesion & $C$ & $\mathrm{kN} / \mathrm{m}^{2}$ & 2.7 & ASTM D3080-11 [26] \\
\hline Friction angle & $\varphi$ & $\left({ }^{\circ}\right)$ & 37 & \\
\hline Elasticity modulus & $E$ & $\mathrm{kN} / \mathrm{m}^{2}$ & 14.9 & ASTM D1194 [27] \\
\hline Unit weight & $\gamma$ & $\mathrm{kN} / \mathrm{m}^{3}$ & 16.3 & ASTM D 4254 [28] \\
\hline Relative density & $D_{r}$ & $\%$ & 70 & ASTM D 4253 [29] \\
\hline $\begin{array}{l}\text { Maximum } \\
\text { porosity }\end{array}$ & $e_{\max }$ & $\%$ & 84 & ASTM D 4254 [28] \\
\hline $\begin{array}{l}\text { Minimum } \\
\text { porosity }\end{array}$ & $e_{\min }$ & $\%$ & 56 & ASTM D 4254 [28] \\
\hline
\end{tabular}

Moreover, in order to improve soil-cement columns compressive strength, microsilica additive with different proportions was added to the cement slurry. The properties of the cement and micro silica materials are summarized in Table 2.

\subsection{Salt-sand samples preparation}

A box with dimensions of $2 \times 1 \times 0.8 \mathrm{~m}$ (see Fig. 2) was selected as a chamber for preparation and insertion of sandy soil bed in lab. In the beginning, the salt with specified weight ratios of 5, 10 and $20 \%$ were mixed with sand and afterwards, the sand-salt admixture was poured in $5 \mathrm{~cm}$-layers thicknesses and each layer was compacted using a laboratory roller with $12 \mathrm{~kg}$ weight. After 9 times passing of roller a relative density of $70 \%$ was achieved to provide an acceptable subgrade soil for execution of DSM columns [16]. It should be pointed out that during the compaction process, the in situ dry density measurement was

Table 2 Chemical and physical properties of microsilica, cement and salt

\begin{tabular}{lccc}
\hline Compositions percentage & microsilica & cement & Salt \\
\hline $\mathrm{Sio}_{2}$ & 91.2 & 20.6 & - \\
$\mathrm{Al}_{2} \mathrm{O}_{3}$ & 1.23 & 4.35 & - \\
$\mathrm{Fe}_{2} \mathrm{O}_{3}$ & 0.76 & 4.20 & $<<$ \\
$\mathrm{MgO}$ & 0.33 & 1.94 & 0.914 \\
$\mathrm{CaO}$ & 0.42 & - & 0.358 \\
$\mathrm{SO}_{3}$ & 0.32 & 2.78 & 1.016 \\
$\mathrm{Cl}$ & - & - & 41.841 \\
$\mathrm{~K}_{2} \mathrm{O}$ & - & - & 0.055 \\
$\mathrm{Na}_{2} \mathrm{O}$ & - & - & 55.815 \\
$\mathrm{Physical} \mathrm{properties}$ & & & \\
${\mathrm{Specific} \mathrm{surface}\left(\mathrm{m}^{2} / \mathrm{gr}\right)}_{\mathrm{Particle} \text { average diameter }(\mu \mathrm{m})}$ & 0.15 & 35 & 800 \\
Unit weight $\left(\mathrm{kg} / \mathrm{m}^{3}\right)$ & 200 & 1800 & 2170 \\
\hline
\end{tabular}

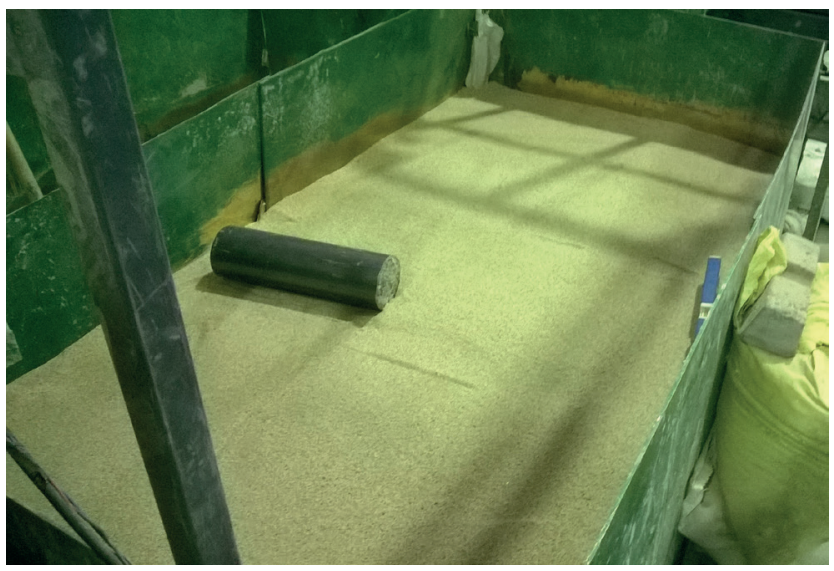

Fig. 2 Salty sand subgrade compaction in chamber using a $12 \mathrm{~kg}$ laboratory roller 
regularly performed to assure the mentioned relative density had been achieved. Also according to ASTM D4254-00 [28] and ASTM D4253-00 [29].

\subsection{DSM apparatus specifications}

As Fig. 3 illustrates, the main parts of laboratory DSM machine are including rotary motor, a 6-blades drilling rod and slurry injection sealing system which are installed on a moving plate. The rotating blades which are coupled to the rotary motor is allowed by the moving plate to be moved vertically. The device's function is to initially rotate the blades clockwise at a speed of $58 \mathrm{rpm}$ and penetrate with a speed of $6 \mathrm{~mm} / \mathrm{s}$ into the soil up to the wanted depth. Then the blades start rotating counterclockwise upward and cement slurry outflows from the nozzle which is located at the end of the blades concurrently. Accordingly, the surrounded soil is mixed with the injected cement slurry using blades' penetration in the soil and consequently DSM columns are formed. It hould also be noted that to supply slurry during the operation, a tank placed at the height of $2.5 \mathrm{~m}$ from the ground floor was used to inject the slurry gravitationally into the hollow tube. To prevent slurry leakage during the operation, a sealing system installed at the top of the rotary rod. It also should be added that during blades penetration process and before starting slurry injection, constant air pressure of 0.5 bar was injected in the rod through sealing system to prevent nozzles' blocking.
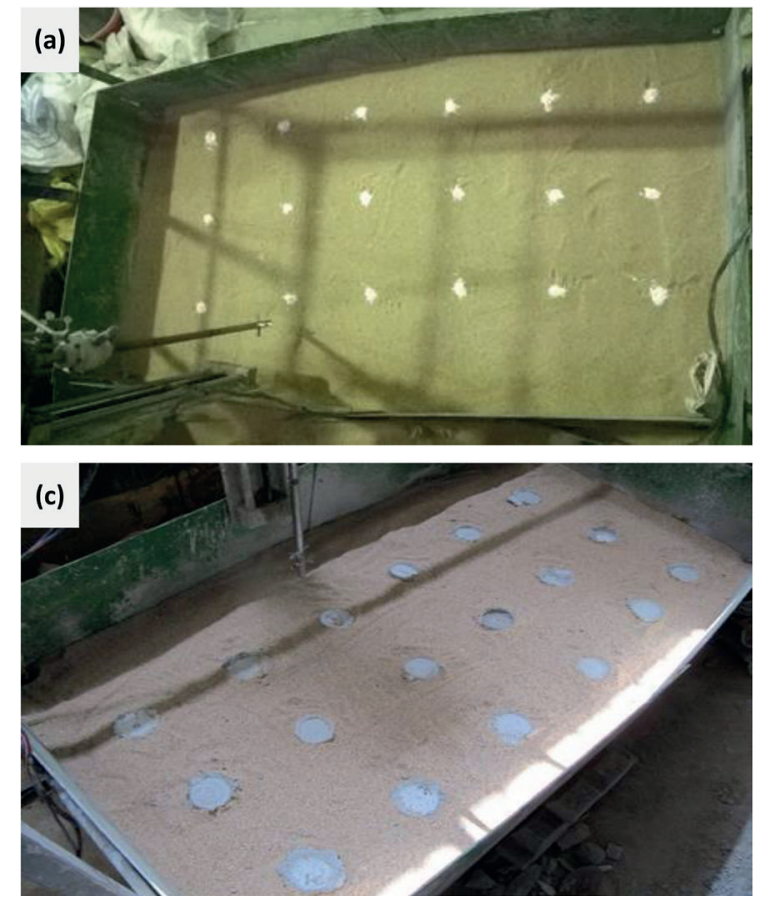

1- rotary motor

2- support

3- moving plate

4- coupling

5- slurry injection system

6- supporting rods

7- auger

8- auger blades
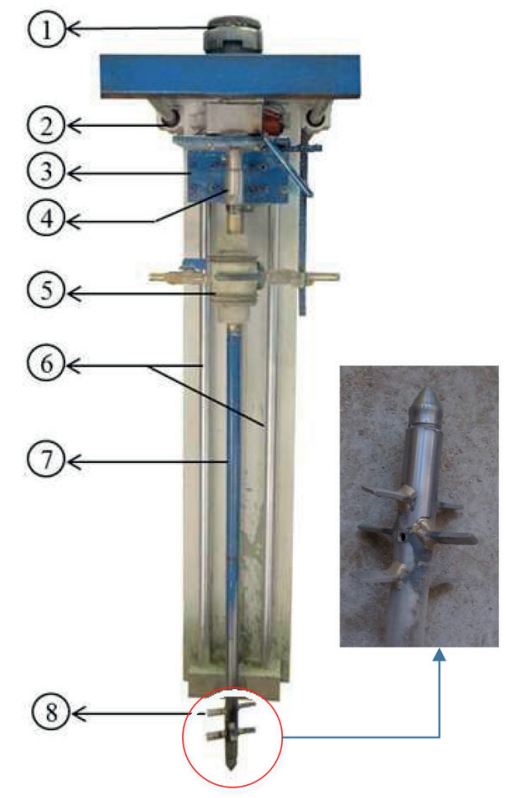

Fig. 3 Deep soil mixing device designed at Iran University of Science and Technology [22]

\subsection{DSM columns execution}

After preparing the subgrade with saline sand in the chamber, location of each column were marked as shown in Fig. 4(a) using chalk. After that, the DSM device was placed at the right positions and then the binder has been uniformly mixed with the salty sand and finally the cement-soil columns were formed with $9 \mathrm{~cm}$ diameter (D) and $40 \mathrm{~cm}$ length (L) (see Fig. 4(a) to (c)).
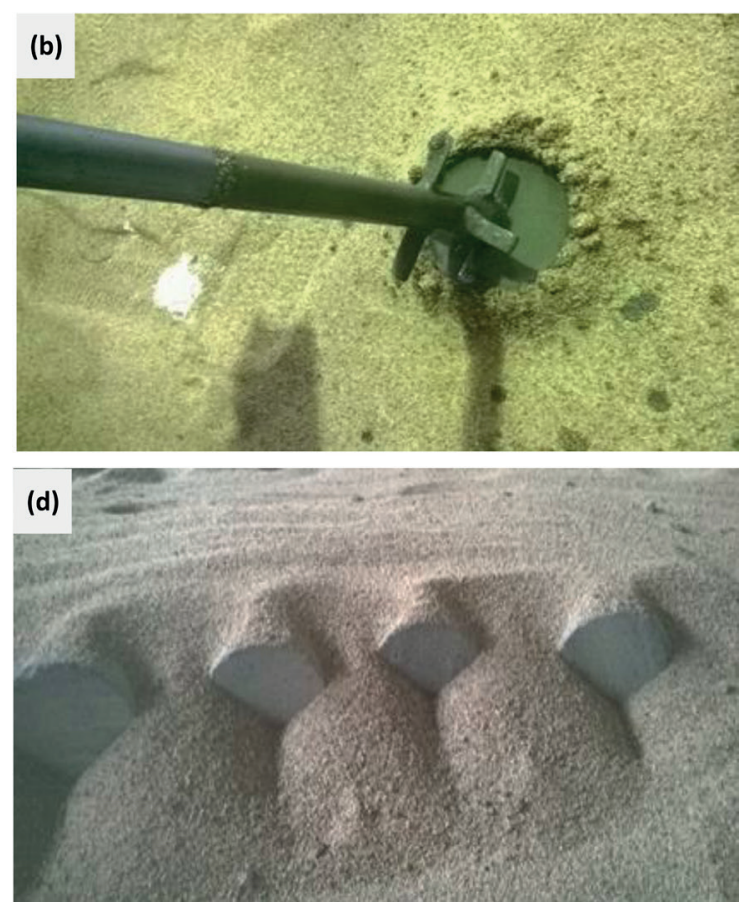

Fig. 4 Differen steps for executing DSM columns in the lab: (a) mark the exact location of the columns; (b) Executing the columns; (c) 18 executed columns in the box; (d) samples curing 
It is worthy to be mentioned that in this study, a cement slurry with water to cement ratio of $1(w / c=1)$ and cement dosage of $200 \mathrm{~kg} / \mathrm{m}^{3}$ is agreed for DSM column execution on the basis of reported results in the previous study of the authors [22]. Although the best microsilica additive percentage in absence of the salt has been reported as $15 \%$ of the cement weight for achieving the best strength in deep mixed columns in SP sand, in presence of the salt this parameter is considered to vary as 5, 10 and $20 \%$ values.

Moreover, it should be pointed out that the DSM columns were executed $30 \mathrm{~cm}$ apart (center to center distance) to prevent interaction and disturbance of the columns. Considering various salt percentages, specimens' ages and micro silica percentages, three DSM columns were executed to ensure the results of experiments. Eventually, 150 DSM columns were constructed and prepared to perform UCS tests. Since the number of specimens was large and also the chamber's space was limited, the columns were removed from the box after 7 days and transferred to a curing place in the lab, where the temperature was constant $\left(25^{\circ} \mathrm{C}\right)$, until the right time (7, 14 and 28 days) of UCS tests (see Fig. 4(d)). As the humidity and salinity affected the results, the samples were surrounded with the same subgrade soil to simulate in situ conditions.

\subsection{Sample preparation and UCS tests}

In order to prepare the samples for UCS test, all columns were cut and prepared in $9 \mathrm{~cm}$ diameter and $20.25 \mathrm{~cm}$ in length $(L / D=2.25)$ to satisfy the criterion of length-to-diameter ratio $2<<L / D<<3$ in accordance with ASTM D216600 standard [31] (Fig. 5(a) to (d)). Afterwards, the samples were subjected to uniaxial compression loading and accordingly, their compressive strength and modulus of elasticity were evaluated. The machine adopted for carrying out uniaxial compression tests was fully automatic which presented a stress-strain diagram for each specimen. It also should be noted that axial load was applied to samples at a constant loading rate of $0.15 \mathrm{MPa} / \mathrm{sec}$ (Fig. 5(e)).
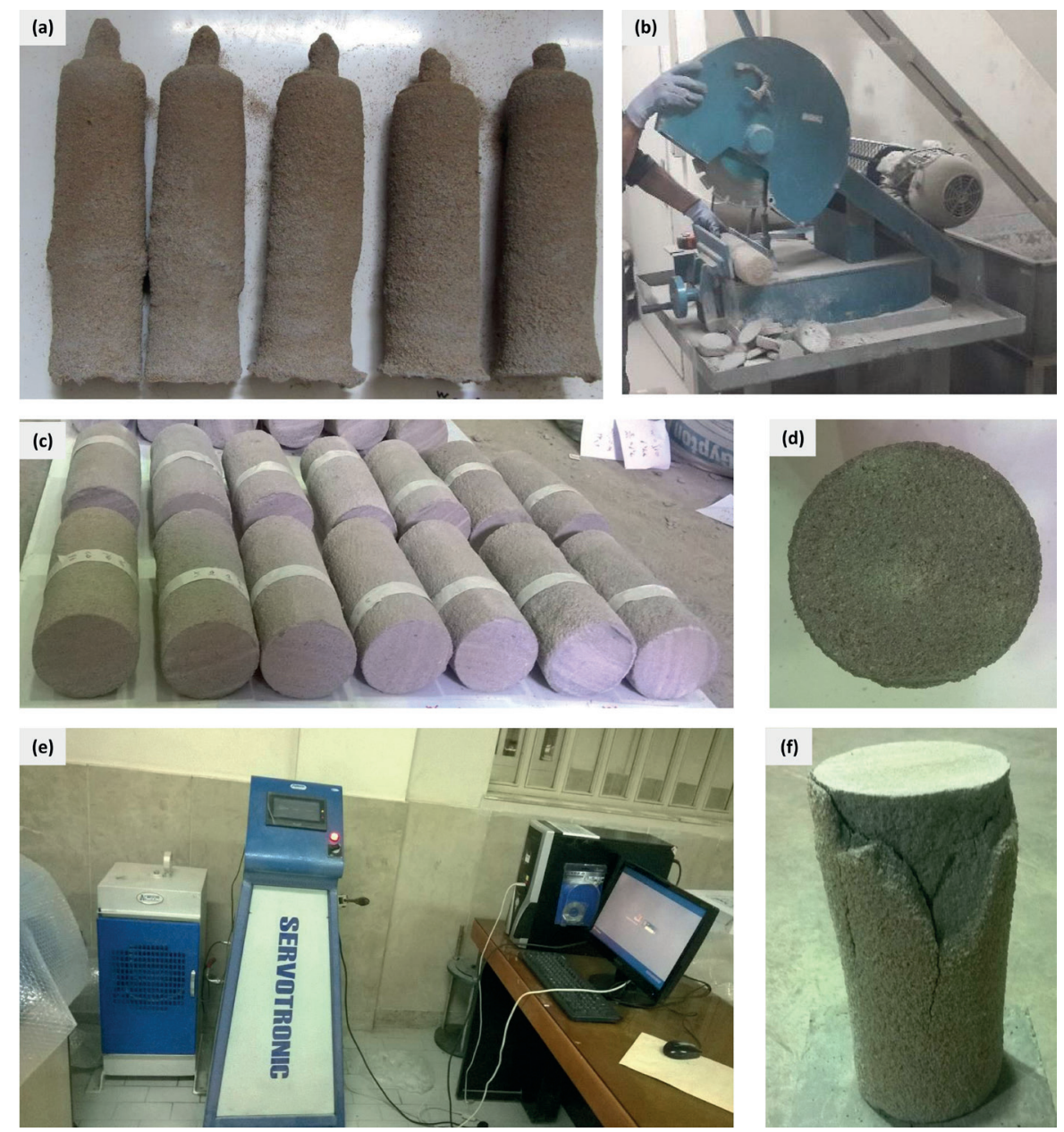

Fig. 5 Different steps of carrying out the uniaxial compressive test: (a) original DSM columns; (b) cutting and capping the samples; (c) prepared samples; (d) automatic loading device; (e) failure mechanism of the DSM specimens 
Fig. 5(e) shows the failure mechanism of cement-soil columns under uniaxial load. This failure mechanism is so close to what happened to rocks samples under axial loading. When a DSM column is subjected to axial load as the sample is compressed axially, transverse expansion occurs simultaneously. Consequently, existing friction between loading jack jaws and two ends of columns causes a restriction for lateral expansion (Poisson's effect) which leads to a wedge type failure for columns [32]. Fig. 6 shows the strain-stress curve for a 28-days DSM sample.

\section{Result and discussion}

In this section, firstly, the impact of salt on the mechanical behavior of DSM columns is discussed. Then, The influence of micro silica additive on both UCS and elasticity modulus of cement-soil columns executed in the saline subgrade will be described. Next, curing time effect on mechanical properties of DSM is presented and finally, the relation between UCS and elasticity modulus of the columns with curing time and amounts of salt and microsilica is determined.

\subsection{The effect of salt on DSM columns behavior}

Fig. 7 illustrates the effect of soil salinity on the mechanical behavior of DSM columns in terms of UCS for three different ages of 7, 14 and 28 days. From the figure it can be seen that for all ages, increasing the amount of salt in the subgrade resulted in decreasing UCS of the columns. The most decline observes for 14 days specimens is about $37 \%$ when $20 \%$ salt in the sand subgrade is included while this value is also about $28 \%$ and $33 \%$ for 28 and 7 days samples. From the chart it can be concluded that except for 14 days samples, by adding salt in the sandy subgrade up

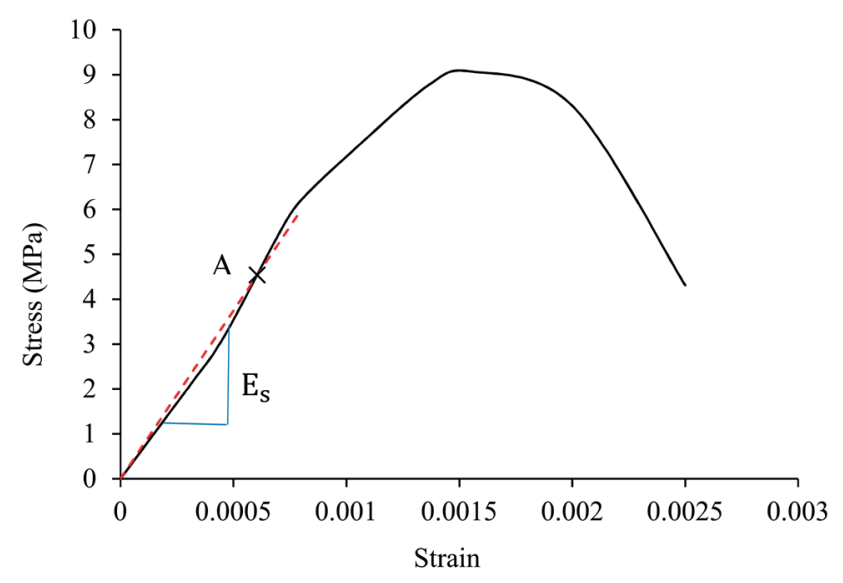

Fig. 6 Stress-strain curve of a 28-day DSM column with W/C of 1, salt and microsilica percentages of 0 to $10 \%$ the UCSs of the columns are smoothly fallen and for more salt percentages, the UCSs values have been significantly affected.

Fig. 8 shows the elasticity modulus, E, of DSM columns versus the amount of salinity of subgrade soil for 7 and 14 and 28 days curing period. According to the graph, although the elasticity modulus of samples has been negligibly decreased by adding 5\% salt, this parameter has declined remarkably by adding $10 \%$ and $20 \%$ salt into the sandy bed. The most drop for the elasticity modulus occurred for 28 days specimens by a $21 \%$ decrease. It also should be pointed out that this value is almost $17 \%$ for both 7 and 14 days samples.

The mechanism of decrease in UCS and elasticity modulus of DSM columns in presence of salt is related to sand replacement by salt which has the lesser mechanical properties in comparison to the sand. It can be understood that as the columns are executed, the salt particles in sand dissolve by the slurry and after drying, they become salt crystal again and place between cement bonds and sand particles. To be more specific and investigate the reason, the SEM image of a sample with $20 \%$ salt was prepared (Fig. 9).

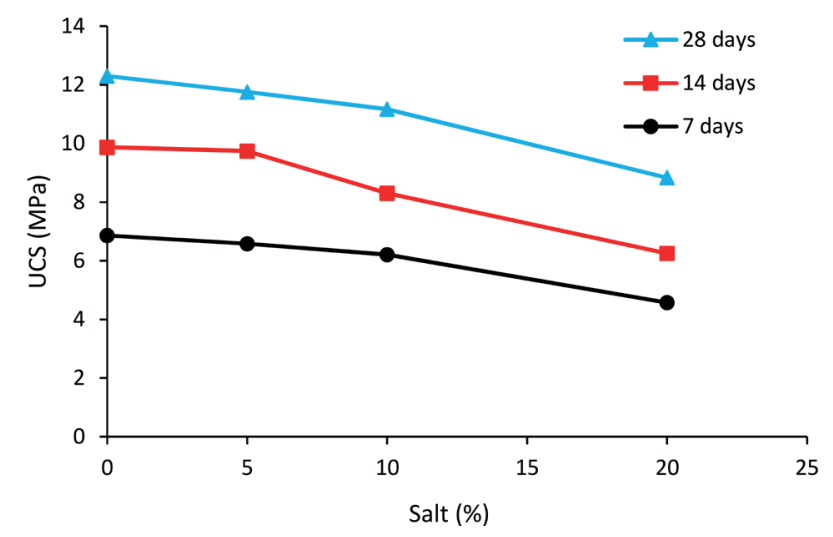

Fig. 7 The effect of salinity on UCS of DSM columns at various ages

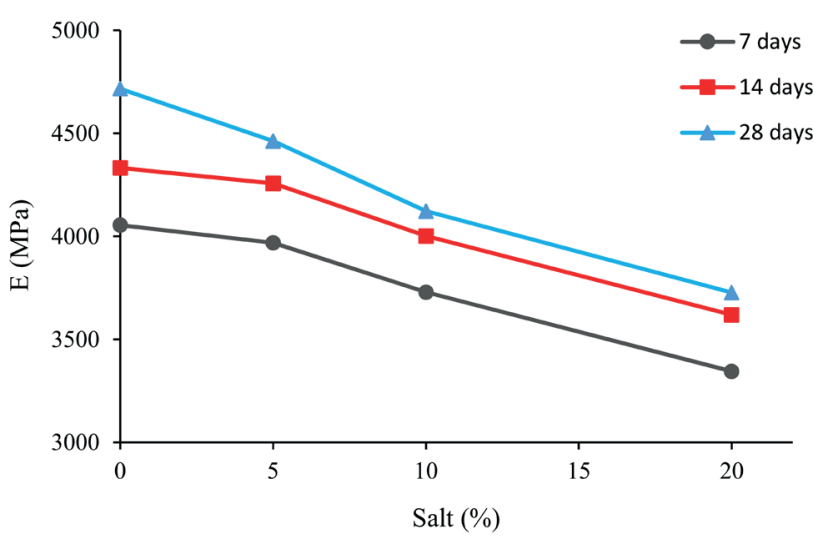

Fig. 8 Elasticity modulus of DSM columns versus amount of salinity 
In addition to having weaker mechanical properties than cement and sand particles, these salt crystals with cubic microstructure cannot form an integrated bond with needle-shaped structures of cement particles which result in weakening of the specimen's UCS and elasticity modulus. From a chemical point of view and based upon what investigated by Xing et al. [24] $\mathrm{Cl}^{-}$has a negative effect on the strength of saline soil-cement in short, intermediate and long-terms. According to this study, soft $\mathrm{Ca}_{2} \mathrm{Al}(\mathrm{OH})_{6} \mathrm{Cl}\left(\mathrm{H}_{2} \mathrm{O}\right)$, as result of interaction between $\mathrm{Cl}^{-}$and $\mathrm{Ca}^{+2}$ and $\mathrm{Al}^{+3}$, has no coherence function and the deposits on the soil grains prevent them to being combined with $\mathrm{Ca}(\mathrm{OH})_{2}$ to increase the strength of soil-cement-soil.

\subsection{Effect of microsilica on UCS of DSM columns}

As mentioned before the soil salinity had an inverse relationship with mechanical properties of cement-soil columns. In this study, microsilica additive has been added in cement slurry by 10,15 and $20 \%$ (by weight of cement) as a treatment to improve the mechanical properties of executed DSM columns in the saline subgrade.

Fig. 10(a) demonstrations the effect of microsilica on UCS of DSM columns with different amount of salt for 28 days samples. The maximum enhancement in the UCS can be assigned to $15 \%$ microsilica additive by $24,19,18$ and $21 \%$ compared to original samples related to DSM columns with $0,5,10$ and $20 \%$ amount of salt respectively. It should be noted that the pervious study carried out by the authors also showed this trend for experimental cement-soil columns [22]. As can be seen from the graph, using microsilica up to $10 \%$ shows insignificant improvement of DSM columns in terms of UCS and also the UCS has slightly declined by adding $20 \%$ microsilica compared to $15 \%$.

Fig. 10(b) depicts microsilica percentage versus elasticity modulus of DSM columns for 0, 5, 10 and 20\% amount of salt. As it can be seen, such as UCS, the most improvement in terms of elasticity modulus has been gained at $15 \%$ microsilica by $34,36,38$ and $42 \%$ for the executed columns in subgrade with $0,5,10$ and $20 \%$ salt respectively. Furthermore, like the UCS trend, the elasticity modulus of the columns has fallen by increasing microsilica from 15 to $20 \%$. Regarding interpretation of the effect of microsilica additive on mechanical properties of DSM columns, SEM images of the soil-cement samples were prepared. Fig. 11 shows two examples of SEM images related to DSM columns without salt at age 28 days with 15 and $20 \%$ microsilica. According to the physical properties of utilized microsilica and cement, the particles of microsilica are approximately 230 times finer than cement ones. As previously investigated by the authors [22], improvement of mechanical properties of DSM columns is vastly dependent on uniform distribution of microsilica particles in empty space between cement particles as fillers. From the

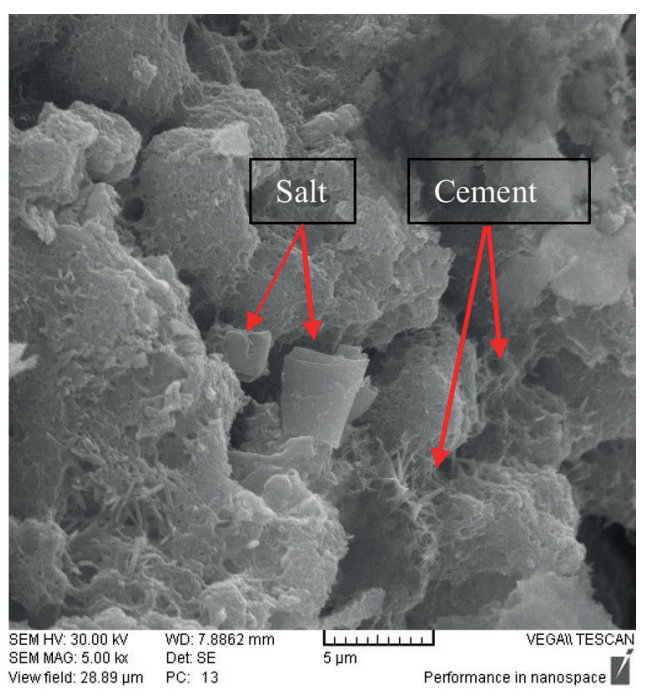

Fig. 9 A SEM image of a 28-day specimen with 20\% salt

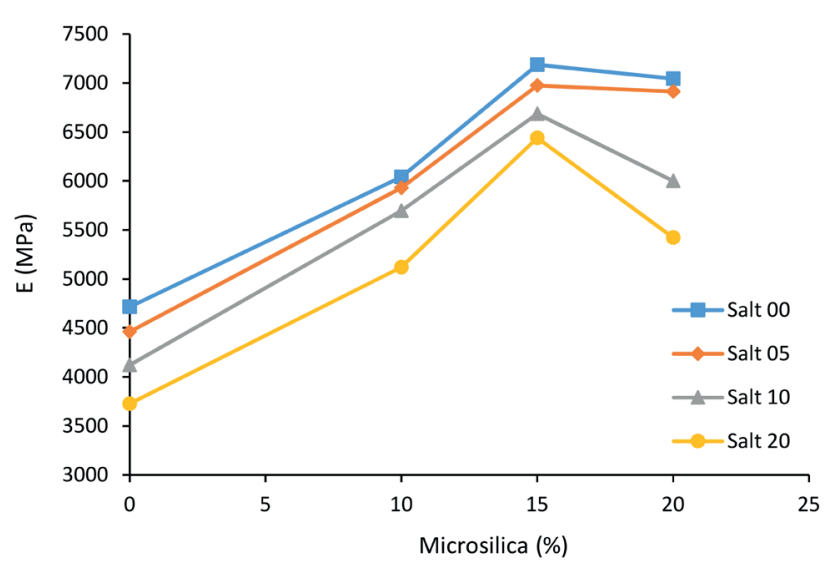

(a)

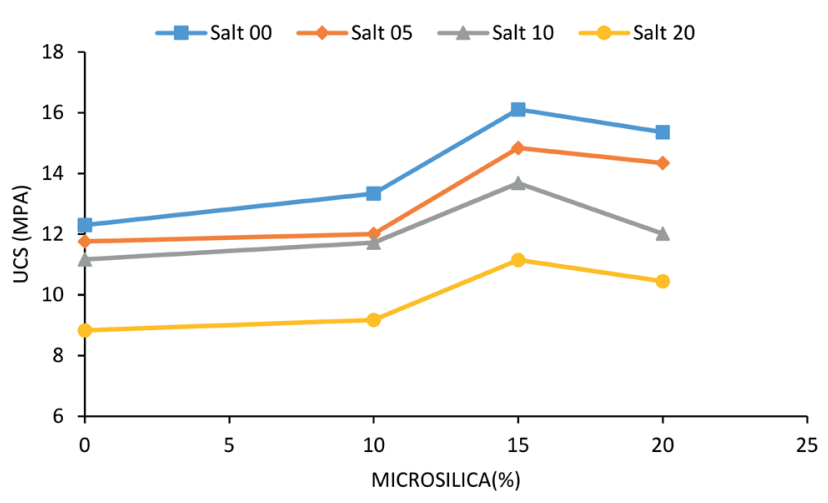

(b)

Fig. 10 The effect of microsilica additive on 28 days cement-soil columns: (a) UCS; (b) elasticity modulus 


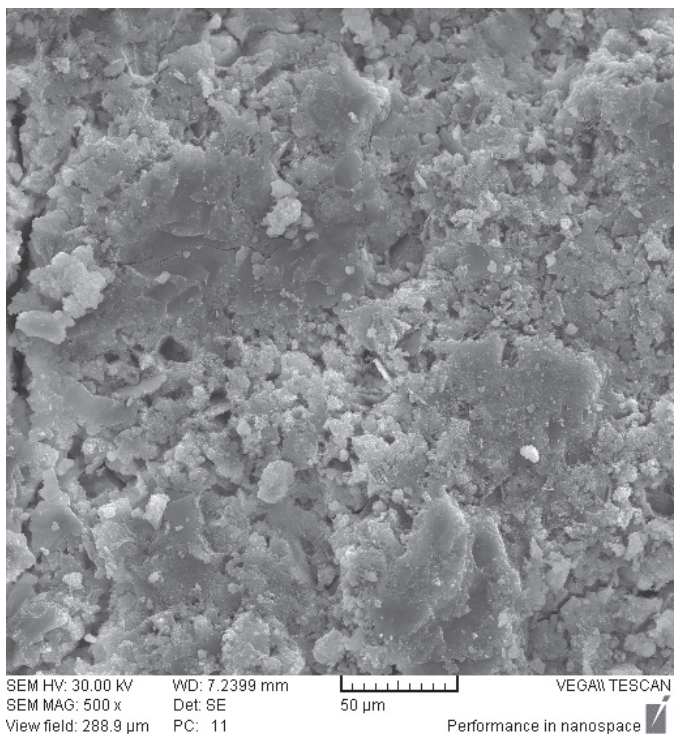

(a)

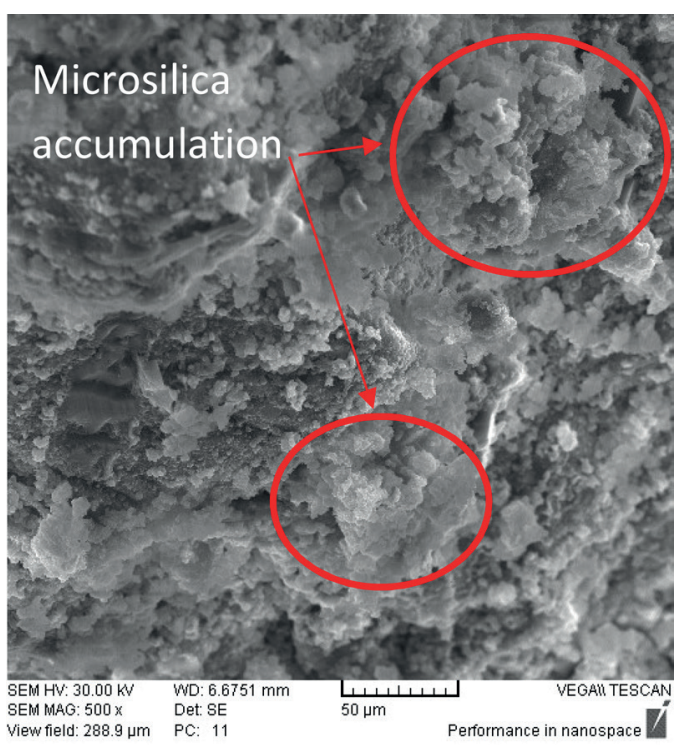

(b)

Fig. 11 SEM images of 28-day DSM columns with $0 \%$ salt for (a) $15 \%$ microsilica; (b) $20 \%$

SEM images it can be seen that adding 15\% microsilica in cement slurry has created a more uniform and integrated structure compared to $20 \%$. The reason is that when the amount of microsilica increases from 15 to $20 \%$, the extra particles which are more than adequate value for filling the empty space between particles, cause inappropriate distribution in particles which resulting in agglomeration of the particles. These agglomerations created in different parts of DSM columns causes weak and susceptible zones to failure. Likewise, these vulnerable zones leads to stress concentration and small creaks during loading process which result in decreasing compressive strength of the samples.

\subsection{The effect of age on UCS and elasticity modulus}

Fig. 12(a) shows the effect of samples' age on compressive strength and elasticity modulus of DSM columns with $15 \%$ micro silica executed in subgrade with $0,5,10$ and $20 \%$ salt. As shown in the figures, mechanical parameters of the specimens i.e. UCS and elasticity modulus has raised due to increase in curing time. The highest values for UCS and elasticity modulus observed at the age of 28 days for samples with $0 \%$ salt. Regarding the UCS parameter, the most increase witnessed by 51, 54, 48 and $40 \%$ for different amounts of $0,5,10$ and $20 \%$ salt respectively with increasing the samples' age from 7 to 28 days. The same enhancement occurred for the elasticity modulus by 27, 31, 29 and $35 \%$ respectively for executed DSM columns in sand subgrade with 0, 5, 10 and 20\% salt content (see Fig. 12(b)).

\subsection{Regression equations}

Finding equations for predicting mechanical properties of DSM columns is one of the important issues which have received much attention by geotechnics researchers.

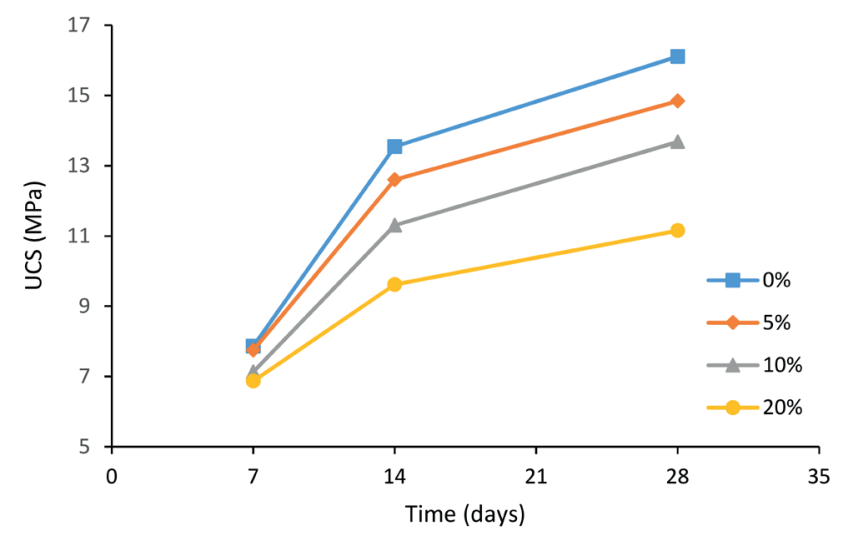

(a)

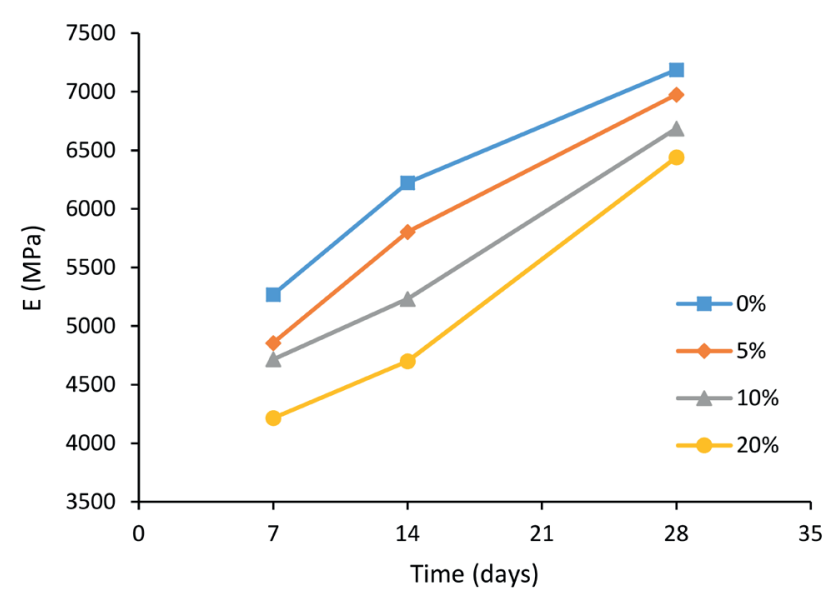

(b)

Fig. 12 The effect of age on mechanical parameters of DSM columns contained 15\% microsilica: (a) UCS; (b) elasticity modulus 
A number of researchers have reported the relation between compressive strength and elasticity modulus of cement-soil columns with water to cement ration, curing time, cement dosage, and soil dry density [33-37, 16, 21]. As a result of an experimental study carried out by the authors [22], two polynomial functions were proposed for compressive strength and elasticity modulus of DSM columns in terms of water to cement ratio, time and microsilica additive. Recently, a series of UCS and California bearing ratio (CBR) tests were carried out on stablized sulfate silty sand with microsilica and lime. According to obtained results, Ghorbani and Hasanzadehshooiili [38] were developed Back Propagation Articial Neural Network (BP-ANN) and Evolutionary Polynomial Regression (EPR) models to predict the UCS values for sulfate silty sand stabilized with different lime and microsilica. Since no study has yet been found to determine the relationship between the mechanical properties of deep mixing columns implemented in salty beds, this study attempts to find out and appropriate equations for compressive strength and elasticity of DSM columns involving salt percentage, age and microsilica additive percentage. To this end, the laboratory test results were imported to SPSS software to establish equations for UCS and elasticity modulus of DSM columns. Afterwards, many regression equations with various were acquired for both UCS and elasticity modulus of the columns based on time, salt and microsilica amount. It should be pointed out that to find out the best predicting equation two factors were considered, $R^{2}$ close to 1 and a low discrepancy between equation and laboratory outcomes. Finally, two Eqs. (1) and (2), were proposed for UCS and elasticity modulus of DSM columns in terms of time $(t)$, salt value $(s)$ and microsilica content $(m)$ for water to the cement of 1 and relative density of $70 \%$. From the values, 0.947 and 0.901 for Eqs. (1) and (2) respectively, it can be claimed that the equations have sufficient confirmations with the obtained lab data.

Moreover, in order to be more precise and judge the equation, the predicted values of UCS and elasticity modulus were drawn versus the measured values in Fig. 13. The closer the data is to the line with a 45-degree slope, the higher the accuracy of the equations. In addition, good visual judgment can be made through two solid lines with $\pm 5^{\circ}$ from the perfect agreement, dashed line [39]. As demonstrated in the figure, most of the points are scattered between two solid lines which indicate high precision of the equations.

$$
\begin{aligned}
U C S= & 3.214+0.531 t+0.002 t^{2} \\
& -0.043 s-0.017 s^{2}+0.001 s^{3}+0.778 m \\
& +0.122 m^{2}+0.004 m^{3}\left(R^{2}=0.947\right)
\end{aligned}
$$

$$
\begin{aligned}
E= & 3829.7-71.72 t+11.02 t^{2} \\
& -0.235 t^{3}-22.66 s-5.67 s^{2}+0.21 s^{3} \\
& -224.54 m+46.33 m^{2}-1.59 m^{3}\left(R^{2}=0.901\right)
\end{aligned}
$$

Where $U C S, E, t, s$ and $m$ are unconfined compression strength $(\mathrm{MPa})$, secant elasticity modulus $(\mathrm{MPa})$ time (day), salt (\%) and micro-silica (\%), respectively.

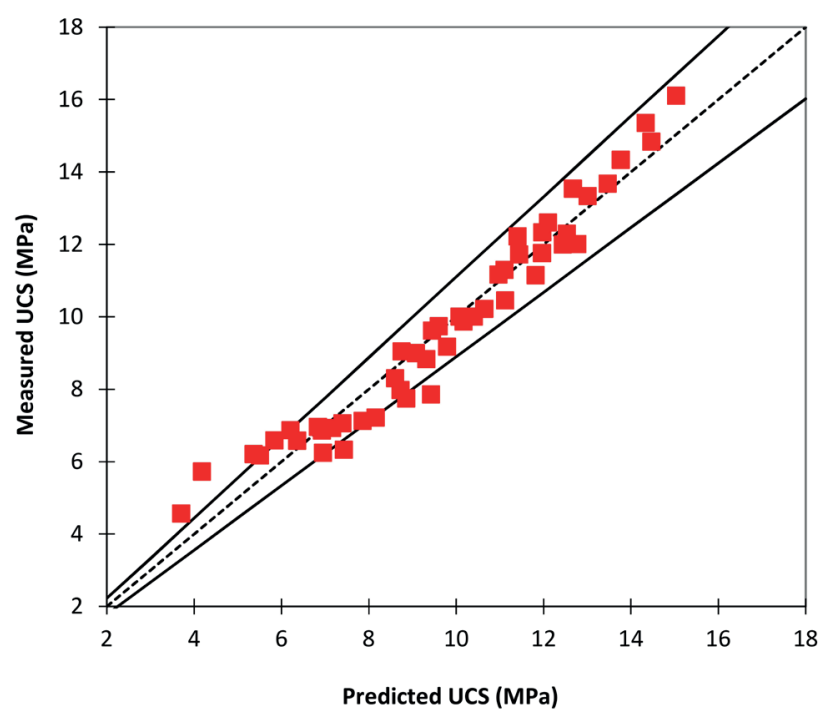

(a)

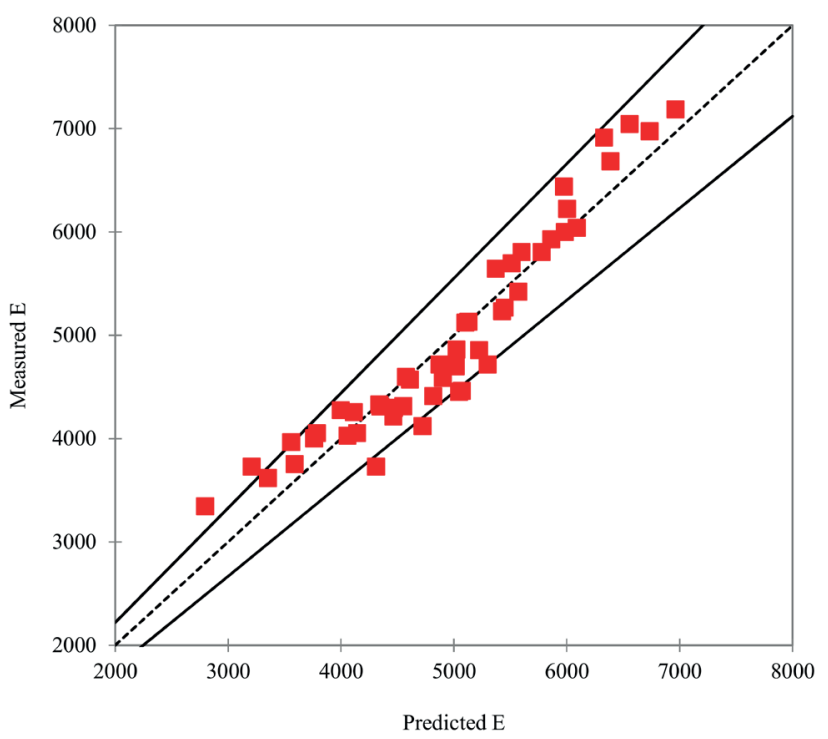

(b)

Fig. 13 Predicted values versus obtained values for DSM columns (a) compressive strength; (b) elasticity modulus 


\section{Conclusions}

The current paper aims to investigate the effect of salinity on the mechanical properties of DSM columns. For this, first of all, four sandy subgrades contain 0, 5, 10 and 20\% salt were prepared at a relative density of $70 \%$. The columns were executed using developed DSM device in the lab environment. It should be noted that the water to cement ratio of 1 was chose for cement slurry as well as 6-blade hollow rod. After capping and preparation of the experimental DSM columns, they were subjected to uniaxial load at three ages of 7, 14 and 28 days to evaluate their compressive strength and elasticity modulus. Microsilica additive also added at percentages of 10, 15 and $20 \%$ in cement slurry to improve mechanical properties of executed DSM columns in the saline subgrades. Following results can be considered as the main achievement of this study:

1. By increasing the amount of salt in sandy subgrade the mechanical parameters of DSM columns have been decreased significantly. The result indicated that most decreases in terms of and elasticity modulus occurred for executed samples in the subgrade with $20 \%$ salt for all ages. These reduction values reported 33,37 and $28 \%$ in terms of UCS and 21 , 17 and $17 \%$ for elasticity modulus corresponding 7, 14 and 28 days specimens, respectively.

2. Analysis of SEM images showed that cubic-shape particles of salt caused discontinuity in cement connections and make them weaker which results in

\section{References}

[1] Petrukhin, V. P., Venkatachalam, G. (eds.) "Construction of structures on saline soils", AA Balkema, Rotterdam, Netherlands, 1993.

[2] Yang, J. S. "Development and prospect of the research on salt-affected soils in China", Acta Pedologica Sinica, 45(5), pp. 837-845, 2008.

[3] Abduljauwad, S. N., Bayomy, F., Al-Shaikh, A.-K. M., Al-Amoudi, O. S. B. "Influence of Geotextiles on Performance of Saline Sebkha Soils", Journal of Geotechnical Engineering, 120(11), pp. 19391960, 1994.

https://doi.org/10.1061/(ASCE)0733-9410(1994)120:11(1939)

[4] Al-Homidy, A. A., Dahim, M. H., El Aal, A. K. A. "Improvement of geotechnical properties of sabkha soil utilizing cement kiln dust", Journal of Rock Mechanics and Geotechnical Engineering, 9(4), pp. 749-760, 2017.

https://doi.org/10.1016/j.jrmge.2016.11.012

[5] Dingwen, Z., Libin, F., Songyu, L., Yongfeng, D. "Experimental investigation of unconfined compression strength and stiffness of cement treated salt-rich clay", Marine Georesources \& Geotechnology, 31(4), pp. 360-374, 2013.

https://doi.org/10.1080/1064119X.2012.690826 deteriorating mechanical properties of cement-soil columns. The results also indicated that although adding microsilica up to $15 \%$ acted as a filler, and make a uniform particle distribution which led to improving mechanical properties of executed DSM columns in the salty subgrade, $20 \%$ micro silica additive resulted in falling both UCS and elasticity modulus because of unsuitable distribution of particles.

3. Adding microsilica in cement slurry led to raising both UCS and elasticity modulus of installed DSM columns in saline soil. It was also understood that using 15\% microsilica (replacement of cement by weight) resulted in the maximum enhancement of 28-day DSM columns in terms of UCS and Young's modulus. These enhancements were 24, 19, 18 and $21 \%$ for UCS and $34,36,38$ and $42 \%$ for elasticity modulus corresponding executed DSM columns in the subgrade with $0,5,10$ and $20 \%$ salt, respectively.

4. According to statistical analysis, two polynomial equations were proposed to predict the UCS and elasticity modulus of DSM columns in terms of salt content, curing time and micro-silica percentage. It should be emphasized that the accuracy of the equations was high enough with values of 0.947 and 0.901 for UCS and elasticity modulus, respectively.

\section{Conflict of interest}

The authors declare that they have no conflict of interest.

[6] Estabragh, A. R., Kouchakzadeh, M., Javadi, A. A. "Treatment of a clay soil deposited in saline water by cement", European Journal of Environmental and Civil Engineering, 25(8), pp. 1521-1537, 2019. https://doi.org/10.1080/19648189.2019.1584769

[7] Han, P., Wang, S., Chen, F. Y., Bai, X. "Mechanism of cement-stabilized soil polluted by magnesium sulfate", Journal of Central South University, 22(5), pp. 1869-1877, 2015.

https://doi.org/10.1007/s11771-015-2706-4

[8] Liu, Y., Wang, Q., Liu, S., ShangGuan, Y., Fu, H., Ma, B., Chen, H., Yuan, X. "Experimental investigation of the geotechnical properties and microstructure of lime-stabilized saline soils under freeze-thaw cycling", Cold Regions Science and Technology, 161, pp. 32-42, 2019.

https://doi.org/10.1016/j.coldregions.2019.03.003

[9] Moayed, R. Z., Izadi, E., Heidari, S. "Stabilization of saline silty sand using lime and micro silica", Journal of Central South University, 19(10), pp. 3006-3011, 2012.

https://doi.org/10.1007/s11771-012-1370-1 
[10] Zhang, S., Yang, X., Xie, S., Yin, P. "Experimental study on improving the engineering properties of coarse grain sulphate saline soils with inorganic materials", Cold Regions Science and Technology, 170, Article number: 102909, 2020. https://doi.org/10.1016/j.coldregions.2019.102909

[11] Jayasekera, S., Hall, S. "Modification of the properties of salt affected soils using electrochemical treatments", Geotechnical and Geological Engineering, 25(1), Article number: 1, 2007. https://doi.org/10.1007/s10706-006-0001-8

[12] Yu, Z., Xu, G., Kang, X., Liu, Y., Zhang, F., Zhang, X. "Unconfined Compressive Strength of Sulphate Saline Soil with Different Salt Content and Lime Proportion", Electronic Journal of Geotechnical Engineering, 21(26), pp. 10203-10214, 2016.

[13] Haofeng, X., Feng, X., Feng, Z. "Improvement for the strength of salt-rich soft soil reinforced by cement", Marine Georesources \& Geotechnology, 36(1), pp. 38-42, 2018. https://doi.org/10.1080/1064119X.2016.1278064

[14] Al-Tabba, A., Ayotamuno, M. J., Martin, R. J. "Soil mixing of stratified contaminated sands", Journal of Hazardous Materials, 72(1), pp. $53-75,2000$. https://doi.org/10.1016/S0304-3894(99)00158-2

[15] Esmaeil, M., Khajehei, H., Astaraki, F. "The Effectiveness of Deep Soil Mixing on Enhanced Bearing Capacity and Reduction of Settlement on Loose Sandy Soils", International Journal of Railway Research, 4(1), pp. 35-42, 2017.

[16] Esmaeili, M., Gharouni-Nik, M., Khajehei, H. "Evaluation of deep soil mixing efficiency in stabilizing loose sandy soils using laboratory tests", Geotechnical Testing Journal, 37(5), pp. 817-827, 2014. https://doi.org/10.1520/GTJ20130099

[17] Farouk, A., Shahien, M. M. "Ground improvement using soil-cement columns: Experimental investigation", Alexandria Engineering Journal, 52(4), pp. 733-740, 2013. https://doi.org/10.1016/j.aej.2013.08.009

[18] Horpibulsk, S., Rachan, R., Suddeepong, A., Chinkulkijniwat, A. "Strength development in cement admixed Bangkok clay: laboratory and field investigations", Soils and Foundations, 51(2), pp. 239-251, 2011. https://doi.org/10.3208/sandf.51.239

[19] Islam, M., Hashim, R. "Bearing capacity of stabilised tropical peat by deep mixing method", Australian Journal of Basic and Applied Sciences, 3(2), pp. 682-688, 2009.

[20] Larsson, S., Dahlström, M., Nilsson, B. "Uniformity of lime-cement columns for deep mixing: A field study", Proceedings of the Institution of Civil Engineers - Ground Improvement, 9(1), pp. $1-15,2005$.

https://doi.org/10.1680/grim.9.1.1.58541

[21] Liu, S. Y., Zhang, D. W., Liu, Z. B., Deng, Y. F. "Assessment of unconfined compressive strength of cement stabilized marine clay", Marine Georesources and Geotechnology, 26(1), pp. 19-35, 2008. https://doi.org/10.1080/10641190801937916

[22] Esmaeili, M., Astaraki, F., Khajehei, H. "Laboratory Investigation on the effect of microsilica additive on mechanical properties of deep soil mixing columns in loose sandy soils", European Journal of Environmental and Civil Engineering, 24(3), pp. 321-335, 2017. https://doi.org/10.1080/19648189.2017.1382394
[23] Stacho, J., Sulovska, M. "Numerical Analysis of Soil Improvement for a Foundation of a Factory Using Stone Columns Made of Different Types of Coarse-grained Materials", Periodica Polytechnica Civil Engineering, 63(3), pp. 795-803, 2019.

https://doi.org/10.3311/PPci.13727

[24] Xing, H., Yang, X., Xu, C., Ye, G. "Strength characteristics and mechanisms of salt-rich soil-cement", Engineering Geology, 103(1-2), pp. $33-38,2009$.

https://doi.org/10.1016/j.enggeo.2008.07.011

[25] Cheng, L., Cord-Ruwisch, R., Shahin, M. A. "Cementation of sand soil by microbially induced calcite precipitation at various degrees of saturation", Canadian Geotechnical Journal, 50(1), pp. 81-90, 2013. https://doi.org/10.1139/cgj-2012-0023

[26] ASTM "ASTM D3080-11 / D3080M-11 Standard Test Methods for Direct Shear Test of Soils under Consolidated Drained Conditions", ASTM International, West Conshohocken, PA, USA, 2011. https://doi.org/10.1520/D3080_D3080M-11

[27] ASTM "ASTM D1194 Standard Test Method for Bearing Capacity of Soil for Static Load and Spread Footings (Withdrawn 2003)", ASTM International, West Conshohocken, PA, USA, 1994. https://doi.org/10.1520/D1194-94

[28] ASTM "ASTM D4254 - 00(2006) Standard Test Method for Minimum Index Density and Unit Weight of Soils and Calculation of Relative Density", ASTM International, West Conshohocken, PA, USA, 2000.

https://doi.org/10.1520/D4254-00R06

[29] ASTM "ASTM D4253 - 00(2006) Standard Test Method for Maximum Index Density and Unit Weight of Soils Using a Vibratory Table", ASTM International, West Conshohocken, PA, USA, 2006. https://doi.org/10.1520/D4253-00R06

[30] ASTM "ASTM D422-63(2007) Standard test method for particle-size analysis of soils. Annual Book of ASTM Standards", ASTM International, West Conshohocken, PA, USA, 2007. https://doi.org/10.1520/D0422-63R07

[31] ASTM "ASTM D2166-00 Standard Test Method for Unconfined Compressive Strength of Cohesive Soil", ASTM International, West Conshohocken, PA, USA, 2000. https://doi.org/10.1520/D2166-00

[32] Katsuyama, K., Vutukuri, V. S. "Introduction to Rock Mechanics", Industrial Publishing \& Consulting, Inc., Tokyo, Japan, 1994.

[33] Asturias, R. P., Lorenzo, G. A. "Laboratory and full-scale simulations of the behaviour of reinforced cement-admixed non-plastic soil for deep mixing applications", International Journal of Scientific Engineering and Technology, 4(5), pp. 286-289. [pdf] Available at: http://ijset.com/publication/v4/064.pdf

[34] Bergado, D. T., Lorenzo, G. A. "Economical Mixing Method for Cement Deep Mixing", In: Geo-Frontiers Congress 2005, Austin, TX, USA, Jan. 24-26, 2005. https://doi.org/10.1061/40783(162)12

[35] Consoli, N. C., Winter, D., Rilho, A. S., Festugato, L., dos Santos Teixeira, B. "A testing procedure for predicting strength in artificially cemented soft soils", Engineering Geology,195, pp. 327-334, 2015.

https://doi.org/10.1016/j.enggeo.2015.06.005 
[36] Horpibulsuk, S., Miura, N., Nagaraj, T. S. "Assessment of strength development in cement-admixed high water content clays with Abrams' law as a basis", Géotechnique, 53(4), pp. 439-444, 2003. https://doi.org/10.1680/geot.2003.53.4.439

[37] Jaritngam, S., Yandell, W. O., Taneerananon, P. "Development of strength model of lateritic soil-cement", Engineering Journal, 17(1), pp. 69-77, 2013.

https://doi.org/10.4186/ej.2013.17.1.69
[38] Ghorbani, A., Hasanzadehshooiili, H. "Prediction of UCS and CBR of microsilica-lime stabilized sulfate silty sand using ANN and EPR models; application to the deep soil mixing", Soils and Foundations, 58(1), pp. 34-49, 2018.

https://doi.org/10.1016/j.sandf.2017.11.002

[39] Shahin, M. A. "Use of evolutionary computing for modelling some complex problems in geotechnical engineering", Geomechanics and Geoengineering, 10(2), pp. 109-125, 2015. https://doi.org/10.1080/17486025.2014.921333 